\title{
Influence of Positive and Negative Affects on the Academic Engagement of Students in the Initial Education Degree: Predictive Study
}

\author{
Lizeth Nolberto-Quispe $^{1, *}$, Milton Gonzales-Macavilca ${ }^{1}$, Ivan Iraola-Real ${ }^{2}$ \\ ${ }^{1}$ Centre for Interdisciplinary Science and Society Studies, Universidad de Ciencias y Humanidades, Peru \\ ${ }^{2}$ Unit of Investigation of the Faculty of Humanities and Social Sciences, Universidad de Ciencias y Humanidades, Peru
}

Received March 21, 2020; Revised May 6, 2020; Accepted January 25, 2021

\section{Cite This Paper in the following Citation Styles}

(a): [1] Lizeth Nolberto-Quispe, Milton Gonzales-Macavilca, Ivan Iraola-Real, "Influence of Positive and Negative Affects on the Academic Engagement of Students in the Initial Education Degree: Predictive Study," Universal Journal of Educational Research, Vol. 9, No. 5, pp. 994 - 999, 2021. DOI: 10.13189/ujer.2021.090512.

(b): Lizeth Nolberto-Quispe, Milton Gonzales-Macavilca, Ivan Iraola-Real (2021). Influence of Positive and Negative Affects on the Academic Engagement of Students in the Initial Education Degree: Predictive Study. Universal Journal of Educational Research, 9(5), 994 - 999. DOI: 10.13189/ujer.2021.090512.

Copyright $(2021$ by authors, all rights reserved. Authors agree that this article remains permanently open access under the terms of the Creative Commons Attribution License 4.0 International License

\begin{abstract}
This research aims to identify the influence of positive affects (AP) and negative affects (AN) on academic engagement (agentic, affective, behavioral and cognitive) in students of the Initial Education degree at a private university in Lima - Peru. The sample is made up of 148 students $(100 \%$ women), from the first to the third cycle between 16 and 52 years of age (Mage $=26.20, \mathrm{SD}=$ 6.53). The results revealed that the students having a positive affect will be able to have a greater engagement in their academic activities. Otherwise if the negative affects prevail, it will influence in a negative way. Likewise, it is concluded that positive affects (PA) positively predict with behavioral engagement $(\beta=.42 ; p<.05)$, affective engagement $(\beta=.37 ; \mathrm{p}<.05)$ and cognitive engagement $(\beta$ $=.34 ; \mathrm{p}<.05)$. Finally, in the Sobel test mediation model, it significantly confirmed that positive affects predict behavioral involvement when mediated by affective engagement. Under this premise, the question arises: How can positive affect be reinforced in the classroom for those students in initial education? How can you help those students who have negative affects? Or What can university teachers do to reinforce and encourage this enthusiasm for studies? In order to foster and incentivize positive affects in university students, it is necessary for teachers to provide an adequate climate within the classroom; and, as a higher institution, it is necessary to find suitable teachers, who do not impose themselves, who
\end{abstract}

do not raise their voices, who do not intimidate, who do not condition the student, but rather motivate them to study for personal interest.

Keywords Positive Affects, Negative Affects, Academic Engagement, Initial Education Career

\section{Introduction}

In daily life, whether the different activities are carried out in a school, the community, the university or in the workplace, people come to interact in their environment. This interaction can generate affections that can even be shared and spread with others [1], both positively and negatively [2]. These affects are expressed in two ways: positive affects (PA) (joy, enthusiasm, or engagement) that express the degree to which people experience emotions; likewise negative affects (AN) (sadness, fear, anxiety or anger) that represent the degree to which people experience feelings of restlessness [3].

These APs have positive effects on well-being, on the development of personal engagement and academic performance [4], since they are characterized by the high level of energy, concentration and dedication that people give them, above all it reflects how happy and enthusiastic 
they are. feel [5]; and ANs such as anxiety or stress negatively affect the general functioning of students [6], due to the different academic demands they face. However, before AN they must have the capacity to resolve them optimally, with the sole purpose of maintaining adequate academic performance and meeting the established goal [7].

These two opposite poles (AP and AN) are closely related to well-being, mental health [6], and are also of vital importance in future teachers [4]. And all the more so, because the female teaching population is more prone to psychiatric problems when pursuing a professional career [8]. That is why, it is important to investigate it in university students of the careers of education who will be the future Peruvian teachers. In this way, strengthening their ability to face any type of difficulty, for which it is necessary to avoid having negative positions, leaving aside discouragement and depression [9].

Faced with this situation that occurs in the university student, the term of engagement appears, which is based on positive psychology, whose fundamental aspect is to have the impetus, in order to remove the existence of that negative energy, such as fatigue and the disorder [10], [11]. Although it is true, the engagement occurs in the labor field; however, the different activities that students carry out are considered as a type of work that is known as academic engagement [12]. Likewise, academic engagement is the degree to which students are actively involved in learning and demonstrating the complete opposite of lack of interest. For this reason, John Marshall Reeve conceives of engagement as the motivation of students to carry out different academic activities; being able to analyze in four types of engagement that are: the cognitive, the behavioral, the affective and the identical [13].

Cognitive engagement refers to when the student is involved in his studies using planned strategies to achieve optimal learning [13]. Behavioral engagement is reflected when the student begins his academic activities with effort, concentration, attention or persistence and constant participation in class [14]. Likewise, affective engagement is expressed when the student shows interest, pleasure and enthusiasm for new academic challenges [15], [16]. And, finally, the agentic engagement, in which the student shows his wishes and needs by giving verbal contributions, thus expressing his needs with the aim of a pleasant environment [17], [18].

\section{Difference between positive affects and affective engagement}

Previously, positive affects and affective engagement were mentioned, so it is important to clarify the difference between the two. For this, it must be understood that positive affects at the first sight can be directly related to affective engagement, however, these two variables have definitions and a point of view that makes them different. This requires that positive affect (PA) represents "the extent to which an individual feels enthusiastic, active and alert", while negative affect (AN) "is characterized by sadness and lack of spirit" [19], both expressing themselves in life in general. On the other hand, the affective engagement for Reeve [16] is expressed in the academic field when the student shows interests and expresses positive emotions when performing tasks [16]; likewise, it refers to the affiliation of the student with his career and the enthusiasm he shows in the face of educational challenges [18].

This positive affect refers to a state in which the individual is in order to later demonstrate it towards studies, and this is complemented by the affective engagement so that it can be reflected in different academic activities. In other words, positive affect is going to be related to affective engagement to study; however, it should be noted the difference that enthusiasm, joy, engagement to daily life in general or to all people is one thing and study is another thing (affective engagement). Therefore, it can be concluded that positive affects are not equal to academic engagement, however, they must be closely linked for good academic performance.

Therefore, in order to know how affects affect academic engagement, this research aims to analyze the influence of positive affects (AP) and negative affects (AN) on the engagement of students in the initial education professional career of a private university of Lima-Peru.

Thus, according to the objective of the investigation, the following hypothetical (Fig. 1) model is proposed.

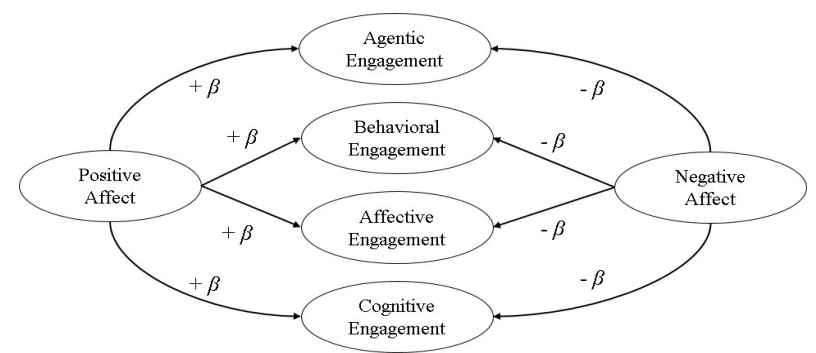

Figure 1. Hypothetical Research Model. The beta $(\beta)$ coefficients represent the predictive relationships.

\section{Methodology}

\section{Participants}

The sample was 148 students (100\% female) between the ages of 16 and 52 (Mage $=26.20, \mathrm{SD}=6.53)$ of the first cycle of studies of the initial education degree at a private university in Lima-Peru.

\section{Measure}


Reeve and Ching-Mei Academic Engagement Scale [20]. This scale assesses the four dimensions of engagement: agentic, behavioral, cognitive, and emotional. It has 22 items with five response dimensions on the Likert scale. The items were organized as follows to evaluate the four types of engagement: Agentic (items: 1-5); behavioral (items: 6-10); emotional (items: 11-14); and cognitive (items: 15-22). For the present study, the validity tests using exploratory factor analysis (AFE) were satisfactory, so the sample adequacy test of Kayser Meyer and Olkin (KMO) was: .75. Likewise, the reliability with the Cronbach's alpha coefficient was .87; for the cognitive engagement subscale; .86 for the behavioral engagement subscale; of .80 for the affective engagement subscale; of .85 for the identical engagement subscale; and the reliability for the full scale was .75 , proving to be reliable [21].

Scale of Positive and Negative Affect Schedule of López-Gómez, Hervás and Vásquez [22]. This scale evaluates the two polarities of the affects, the AP and the $\mathrm{AN}$, consisting of 20 items, with 5 response dimensions on the Likert scale. The instrument was adapted for university students with an adapted version of 15 items; of which 7 items correspond to AP and 8 to AN [23]. Also, the validity tests were satisfactory, thus the KMO was .71. And for the reliability analysis with the internal consistency method it was observed that the positive affect subscale obtained a Cronbach's alpha coefficient of .66, and for the negative affect subscale it was .78; demonstrating that both scales are reliable [24].

\section{Results}

\section{Relationship between variables}

The analysis of the correlations between the variables was performed using Pearson's rho, thus evaluating the magnitude of the correlation coefficients, taking as a reference the Cohen criteria [25] for the social sciences (mild, $\mathrm{r}=.10-.23$; moderate, $\mathrm{r}=.24-.36$; strong, $\mathrm{r}=.37$ or more); therefore, these criteria are suitable for educational research.

Regarding relationships, Table 1 shows that positive affect has a positive, slight and significant relationship with identical engagement. This means that, if students feel enthusiastic, they could provide contributions in class or feel the motivation to do it. It can also be mentioned that positive affect has a positive, strong and significant relationship with behavioral engagement; In other words, if the students are in a good mood, they could focus, take notes, participate, and be attentive in class. Then, positive affect has a positive, moderate and significant relationship with affective engagement, that is, if the future teacher feels energized, enthusiastic or in a good mood, she could show interest and curiosity to learn new things in class. Finally, positive affect presents a positive, moderate and significant relationship with cognitive engagement, which means that, if the student experiences positive emotions such as self-confidence, this could be associated with the development of planning strategies to obtain learning.

Also, in Table 1, it can be observed that negative affect presents a negative, slight and significant relationship with identical engagement, in other words, the high levels of fear, mistrust or bad mood presented by the students are related to weak wishes to contribute or support teachers during classes. Likewise, negative affect has a negative, moderate and significant relationship with behavioral engagement, that is, if the future teacher is highly anxious, stressed or suspicious, she may have difficulties concentrating during class or vice versa. Also, negative affect has a negative, moderate and significant relationship with affective engagement, in other words, if the student experiences high levels of fear, sadness, or mistrust, he may have weak levels of curiosity or interest in learning new things in the classroom or vice versa. Finally, negative affect has a negative, moderate and significant relationship with cognitive engagement, this can explain why high levels of anxiety, tension or fear are associated with disorganization and the non-planning of educational activities.

Table 1. Pearson correlation coefficients.

\begin{tabular}{|l|c|c|c|c|c|c|}
\hline \multicolumn{1}{|c|}{ Variable } & $\mathbf{1}$ & $\mathbf{2}$ & $\mathbf{3}$ & $\mathbf{4}$ & $\mathbf{5}$ & $\mathbf{6}$ \\
\hline 1. Agentic Engagement & $(.85)$ & & & & & \\
\hline 2. Behavioral Engagement & $.22^{* *}$ & $(.86)$ & & & & \\
\hline 3. Affective Engagement & .14 & $.74 * *$ & $(.80)$ & & & \\
\hline 4. Cognitive Engagement & $.27^{* *}$ & $.69 * * *$ & $.72^{* * *}$ & $(.87)$ & & \\
\hline 5. Positive Affect & $.21^{*}$ & $.42^{* * *}$ & $.36^{* * *}$ & $.34 * * *$ & $(.66)$ & \\
\hline 6. Negative Affect & $-.23^{* *}$ & $-.28^{* *}$ & $-.25^{* *}$ & $-.30^{* * *}$ & $-.33^{* * *}$ & $(.78)$ \\
\hline
\end{tabular}

Note. ${ }^{*},{ }^{* *},{ }^{* * *}$ shows significant relationships. ${ }^{*} p<.05,{ }^{* *} p<.01,{ }^{* * *} p<.001$ (bilateral). 
The results can be summarized as follows (Fig. 2), thus confirming the hypothetical model.

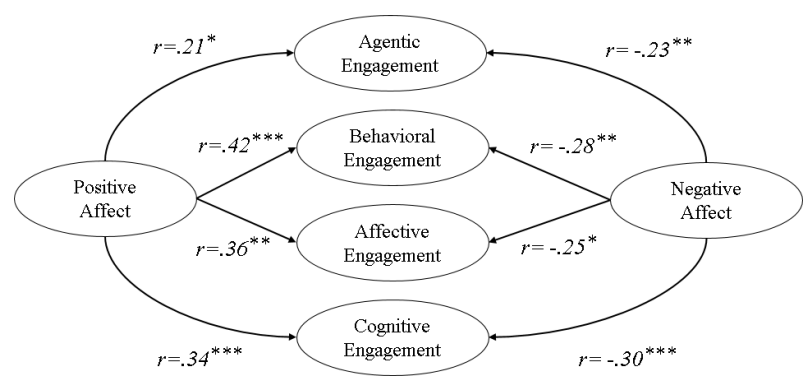

Figure 2. Relationship analysis in the hypothetical research model.

\section{Linear regression}

After the analysis of the relationships between the variables, a multiple linear regression analysis was performed [26] and it was confirmed that of the two affects (AP and AN), that the positive affect predicts behavioral compromise (Table 2). Thus, it was found that in the model of the two predictor variables, the variable positive affect $(\beta=.37, \mathrm{p}<.05)$, positively predicts behavioral engagement. This means that students who feel excited, active, optimistic, comfortable or satisfied can be expected; They will pay more attention, be focused and persist in their studies.

Table 2. Regression Beta Coefficients.

\begin{tabular}{|c|c|c|}
\hline \multirow{2}{*}{ Predictor variables } & \multicolumn{2}{|c|}{ Dependent variable } \\
\cline { 2 - 3 } & \multicolumn{2}{|c|}{ Behavioral engagement } \\
\hline Positive affect & $\boldsymbol{R}^{2}=.17$ & $\boldsymbol{\beta}=.37 * * *$ \\
\hline
\end{tabular}

Note. $* \mathrm{p}<.05, * * \mathrm{p}<.01, * * * \mathrm{p}<.001$.

Then in Table 3, it is observed that the variable positive affects positively and significantly predicts affective engagement $(\beta=.37, \mathrm{p}<.01)$, indicating that students with positive affects (well-being, joy, optimism, etc.) will present interest and enthusiasm for their academic activities.

Table 3. Regression Beta Coefficients.

\begin{tabular}{|c|c|c|}
\hline \multirow{2}{*}{ Predictor variables } & \multicolumn{2}{|c|}{ Dependent variable } \\
\cline { 2 - 3 } & \multicolumn{2}{|c|}{ Affective engagement } \\
\hline Positive affect & $\boldsymbol{R}^{2}=.13$ & $\boldsymbol{\beta}=.37 * * *$ \\
\hline
\end{tabular}

Note. ${ }^{*} \mathrm{p}<.05, * * \mathrm{p}<.01, * * * \mathrm{p}<.001$.

Likewise, in Table 4, it is evident that positive affect again predicts cognitive engagement $(\beta=.34, \mathrm{p}<.01)$. From the result of this regression, it can be inferred that students who have a positive affect (well-being, joy, optimism, etc.) will present a planned learning and organize themselves when studying.
Table 4. Regression Beta Coefficients.

\begin{tabular}{|c|c|c|}
\hline \multirow{2}{*}{ Predictor variables } & \multicolumn{2}{|c|}{ Dependent variable } \\
\cline { 2 - 3 } & \multicolumn{2}{|c|}{ Cognitive engagement } \\
\hline Positive affect & $\boldsymbol{R}^{2}=.12$ & $\boldsymbol{\beta}=.37 * * *$ \\
\hline
\end{tabular}

Note. $* \mathrm{p}<.05, * * \mathrm{p}<.01, * * * \mathrm{p}<.001$.

\section{Mediation Model}

Linear regression analysis showed significant predictions of positive affect with behavioral, emotional, and cognitive engagement; It is also known that at the intra-scale level, the types of engagement are predicted in a positive and significant way. With these results, a mediation model is proposed to estimate the effect between positive affect (predictive variable) on behavioral engagement (output variable) mediated by affective engagement (mediator variable).

To complete the mediation model, the steps of Baron and Kenny were used [27]. Firstly, the predictive value of the positive affects of the students and their affective engagement were analyzed. The second step was to examine the predictive value of positive affect with behavioral engagement. The third step was to study the predictive value of affective engagement and behavioral engagement. The fourth step analyzed the predictive value of positive affects and emotional engagement (both variables) on behavioral engagement. Significant prediction coefficients corresponding to a mediation model were found in all four steps.

Finally, the confirmation of the mediation model was performed with the Sobel test [28], with which it was observed that the effect of positive affect (predictive variable) on behavioral engagement (dependent variable) is reduced when analyzed as a predictor variable. with affective engagement. All this shows that positive affect predicts the student's behavioral engagement when it is mediated by affective engagement (mediating variable) (Fig. 3). This indicates that positive affects need affective engagement in order to predict adequate levels of behavioral engagement.

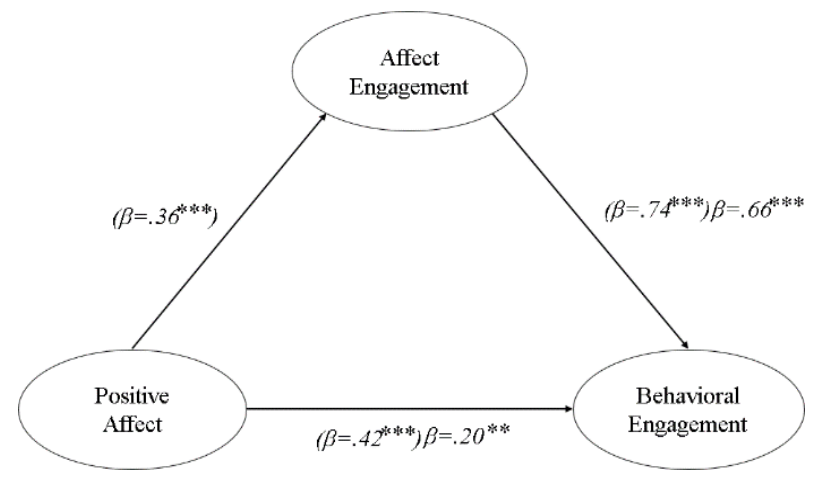

Figure 3. Mediation model. 


\section{Conclusions}

The objective of this study was to analyze the influence of positive and negative effects on academic engagement; and thus, the results showed that positive affect predicts the behavioral, affective and cognitive component. Likewise, in the mediation model, positive affect cannot predict behavioral engagement if previously this affect is not mediated by positive emotions in the student's life; In other words, the positive effects of students' everyday life predict behavioral engagement only if it is mediated by interest or enjoyment in study or academic tasks (affective engagement).

Faced with the results, university students in the initial education degree must present or develop positive affection. This situation makes us reflect as teachers; first, to identify students with positive effects and to maintain them; and second, to find students who have negative effects and to try to gradually modify them. Likewise, it is necessary to awaken the affective engagement, that is, awakening in them the motivation, the interest, the enthusiasm and the pleasure for the study.

Under this premise, the question arises: How can positive affect be reinforced in the classroom for those students in initial education? How can you help those students who have negative affects? Or What can university teachers do to reinforce and encourage this enthusiasm for studies? In order to foster and incentivize positive affects in university students, it is necessary for teachers to provide an adequate climate within the classroom; and as a higher institution, it is necessary to find suitable teachers, who do not impose themselves, who do not raise their voices, who do not intimidate, who do not condition the student, but rather motivate them to study for personal interest. This could indicate that in the first years or the first two cycles they have to make a filter with those teachers, so that the student, together with the teacher, can work hand in hand and identify those who have negative effects and reinforce with those who do have positive affects.

From this, the following question can be asked: What can be done so that those students who have positive affects show affective engagement? For example: When a student is optimistic, in a good mood, empathetic, calm in the face of the problems raised and studies for evaluations, there he is showing that positive affects prevail in him; however, he does not carry out the academic tasks by himself, and he expects to be told what they have to do. It is there that the teacher must be very observant in order to work with that student and reinforce the affective engagement. This is a need that teachers must work on and, being open to future research on how positive affect can become affective engagement.

\section{REFERENCES}

[1] Gil, E., Llorens, S. and Torrente, P.: Compartiendo afectos positivos en el trabajo: el rol de la similitud en los equipos. Pensamiento Psicológico, 13 (1), 93-103 (2015).

[2] Hatfield, E., Rapson, R. L. and Le, Y. L.: Emotional Contagion and Empathy. In J. Decety \& W. Ickes. Editor: The Social Neuroscience of Empathy. Cambridge (2009).

[3] Porto, A., Fonseca, D., Ferraz, R., Murgo, C.: Relações entre afetos positivos e negativos e os cinco fatores de personalidade, 20(2), 92-1001 (2015).

[4] Pinedo, R., Arroyo, M. and Caballero, C.: Afectividad positiva y negativa en el futuro docente: relaciones con su rendimiento académico, salud mental y satisfacción con la vida, 20, 11-26 (2017).

[5] Watson, D., Clark, L, Carey, and G.: Development and validation of brief measures of positive and negative affect: The PANAS scales, Journal of Personality and Social Psychology, 54, 1063-1070 (1988).

[6] Alkhalaf, A.; Positive and negative affect, anxiety, and academic achievement among medical students in Saudi Arabia. International Journal of Emergency Mental Health and Human Resilience, 20 (2), 397 (2018).

[7] Caballero, C., Abello, R. and Palacio, J.: Relación del Burnout y el rendimiento académico con la satisfacción frente a los estudios en estudiantes universitarios, Avances en Psicología Latinoamericana, 25 (2), 98-111 (2007)

[8] Bermejo-Toro, 1. and Prieto-Ursúa, M.: Absenteeism, burnout and symptomatology of teacher stress: sex differences. International Journal of Educational Psychology, 3 (2), 175-201 (2014).

[9] Gutiérrez, J., Montoya, L., Toro, B., Briñón, M., Rosas, E. and Salazar, L.: Depresión en estudiantes universitarios y su asociación con el estrés académico, 24 (1), 7-17 (2010).

[10] Parra, P.: Relación entre el nivel de Engagement y el rendimiento académico teórico/práctico. Revista de Educación en Ciencias de la Salud, 7(1), 57-63 (2010).

[11] Vera, B.: Psicología Positiva: Una nueva forma de entender la psicología, Papeles del psicólogo, 27(1), 3-8 (2006).

[12] Ouweneel, E. and Schaufeli, W.: Believe, and you will achieve: changes over time in self efficacy, engagement, and performance. Applied Psychology: Health and Well-Being, 5(2), 225- 247 (2013).

[13] Reeve, J.: A Self-determination Theory Perspective on Student Engagement. Handbook of Research on Student Engagement, 149-172 (2012).

[14] Skinner, E., Kinderman, T. and Furrer, C.: A motivational perspective on engagement and disaffection; Conceptualization and assessment of children's behavioral and emotional participation in academic activities in the classroom, Educational and Psychological Measurement, 69(3), (2009).

[15] Skinner, E., Furrer, C., Marchand, G. and Kinderman, T.: Engagement and disaffection in the classroom: Part of a larger motivational dynamic? Journal of Educational Psychology, 100(4), 765-781 (2008). 
[16] Reeve, J. and Lee, W.: Students' classroom engagement produces longitudinal changes in classroom motivation. Journal of Educational Psychology, 106(2), 527-540 (2013).

[17] Reeve, J.: Understanding motivation and emotion. Iowa, Wiley (2009).

[18] Gonzales-Macavilca, M., Nolberto-Quispe, L. and Iraola-Real, I.: Determining Factors for Getting Good Grades in Engineering Careers. The Case of a Public University in Lima (Peru), Conference on Electrical, Electronics Engineering, Information and Communication Technologies, 1-5 (2019).

[19] Dufey, M. and Fernández, A. M.: Validez y confiabilidad del Positive Affect Schedule (PANAS) en estudiantes universitarios chilenos, Revista Iberoamericana de Diagnóstico y Evaluación, 2(34), 157-173 (2012).

[20] Reeve, J. and Ching-Mei, T.: Agency as a fourth aspect of students' engagement during learning activities, Contemporary Educational Psychology, 36, 257-267 (2011).

[21] Field, A.: Discovering statistic susing SPSS (3era Ed.). Lóndres: Sage publications, (2009).
[22] López-Gómez, I., Hervás, G. and Vázquez, C.: Adaptation of the Positive and Negative Affect Schedule (PANAS) in a Spanish general sample, 1-23 (2015).

[23] Thompson, R.: Development and validation of an internationally reliable short-form of the Positive and Negative Affect Schedule (PANAS), Journal of Cross-Cultural Psychology, 38, 227-242 (2007).

[24] Aiken, R.: Psychological testing and assessment (11th Ed.).Boston: Allyn \& Bacon (2002).

[25] Cohen, J.: A power primer, Psychol. Bull, 112, 155-159 (1992).

[26] Bingham, N. and Fry, J.: Regression: Linear models in statistics. New York: Springer (2010).

[27] Baron, R. and Kenny, D.: The Moderator-Mediator Variable Distinction in Social Psychological Research: Conceptual, Strategic, and Statistical, Journal of Pernality and Social Psychology, 51 (6), 1173-1182 (1986).

[28] Sobel, M.: Asymptotic confidence intervals for indirect effects in structural equation models, Sociological Methodology, 13, 290-312 (1982). 